
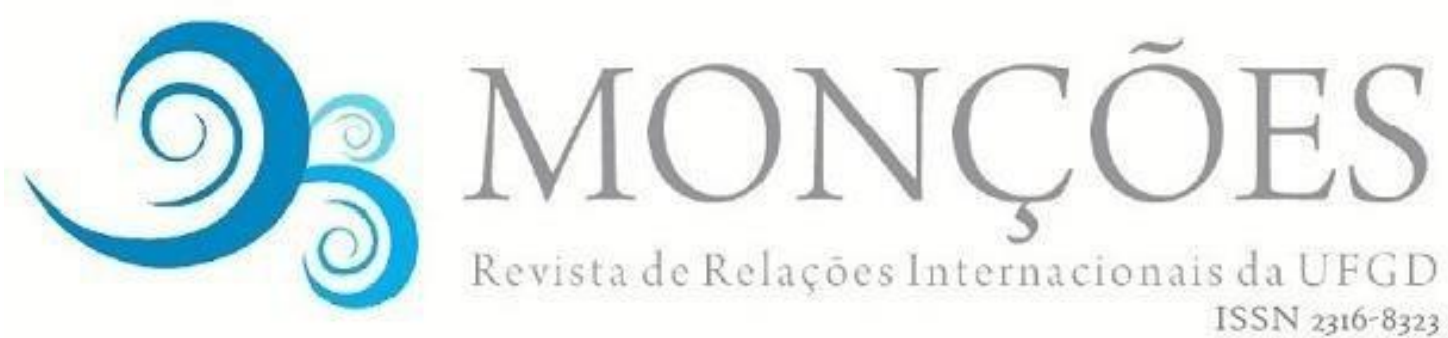

\title{
ACCOUNTABILITY E A ATUAÇÃO INTERNACIONAL DO MUNICÍPIO DE SÃO PAULO
}

\author{
DANILO GARNICA SIMINI \\ Doutorando em Ciências Humanas e Sociais (UFABC), Mestre em Direito (UNESP), \\ Bacharel em Direito (PUC-CAMPINAS). Professor no curso de Relações \\ Internacionais da Universidade de Ribeirão Preto/SP (UNAERP).
}

\begin{abstract}
RESUMO: A atuação internacional de municípios constitui atualmente no Brasil uma importante alternativa em termos de formulação e implementação de políticas públicas, sendo o município de São Paulo um dos pioneiros neste tipo de atuação. Sendo assim, dada a a relevância deste tipo de prática, deve-se questionar se há o controle sobre esta atuação, especific amente, no que se refere à efetivação do dever de prestação de contas por parte dos governantes, bem como em relação à sua responsabilização, principalmente em decorrência da prática de possíveis atos irregulares. Portanto, o trabalho visa investigar se houve, entre os anos de 2013 e 2016, a prática de accountability da atuação internacional do município de São Paulo, implementada através de sua Secretaria de Relações Internacionais e Federativas, por parte do Poder Legislativo, através de sua "Comissão Extraordinária Permanente de Defesa de Direitos Humanos, Cidadania e Relações Internacionais". A pesquisa foi realizada através de duas fases em termos metodológicos, quais sejam, revisão bibliográfica e coleta de dados oriundos do Poder Legislativo.
\end{abstract}

Palavras-chave: accountability; Secretaria Municipal de Relações Internacionais e Federativas de São Paulo; Poder Legislativo; controle.

\section{ACCOUNTABILITY AND INTERNATIONAL ACTION OF THE CITY OF SÃO PAULO}

ABSTRACT: The international action of municipalities is currently an important alternative in Brazil in terms of formulation and implementation of public policies, and the municipality of São Paulo is one of the pioneers in this type of activity. Therefore, given the relevance of this type of practice, one must question whether there is control over this performance, specifically, regarding the effectiveness of the accountability of the government, as well as its accountability, Mainly due to the practice of possible irregular acts. Therefore, the study aims to investigate whether, between 2013 and 2016, the practice of accountability of the international performance of the city of São Paulo, implemented through its Secretariat of International and Federative Relations, by the Legislative Branch, through its "Permanent Extraordinary Commission for the Defense of Human Rights, Citizenship and International Relations". The research was carried out through two phases in methodological terms, namely, bibliographic review and data collection from the Legislative Branch.

Keywords: accountability; Municipal Secretary of International and Federative Relations of São Paulo; Legislative power; control. 


\section{INTRODUÇÃO}

A intensidade do processo de urbanização no Brasil trouxe consequências imediatas na vida daqueles que passaram a residir nas cidades como, por exemplo, a marginalização de parte da população urbana e a falta de qualidade em diversos serviços públicos. Neste contexto, o Município emerge como um importante agente indutor de políticas públicas, assumindo tarefas em diversas áreas relevantes, tais como educação e saúde (MOHN, 2006), assumindo um novo papel na organização nacional. No entanto, deve-se considerar que a atribuição de novas responsabilidades não foi acompanhada da existência de recursos suficientes para que as demandas públicas da população fossem atendidas de modo satisfatório, o que levou a uma certa sobrecarga em relação aos municípios brasileiros, decorrente desta delegação de responsabilidades.

Concomitantemente à atribuição de novas responsabilidades, a Constituição Federal de 1988 conferiu aos municípios brasileiros status de ente federativo. Consequentemente, a Constituição Federal assegurou-lhes autonomia na área política, administrativa, financeira e legislativa. Este contexto de assunção de novas responsabilidades e de autonomia político-jurídica acabou estimulando os municípios brasileiros a atuar internacionalmente como forma de buscar soluções para as dificuldades enfrentadas.

O município de São Paulo é considerado um dos pioneiros em termos de atuação internacional. Este ente subnacional deu início a sua atuação durante o governo Luiza Erundina (PT), com a criação da Coordenadoria de Relações Internacionais, ligada à Secretaria de Negócios Extraordinários. Posteriormente, no ano de 2001, houve por meio da Lei oㅜ 13.165, a criação da Secretaria de Relações Internacionais. Desde o ano de 2013, com o início da administração Fernando Haddad (PT) e a promulgação da Lei Municipal no 15.764/2013, o órgão passou a se chamar Secretaria Municipal de Relações Internacionais e Federativas.

A atuação internacional constitui uma importante alternativa em termos de formulação e implementação de políticas públicas. Sendo assim, dada a sua relevância, deve-se questionar se há o controle sobre esta atuação, especificamente no que se refere à efetivação do dever de prestação de contas 
por parte dos governantes, bem como em relação à sua responsabilização, principalmente em decorrência da prática de possíveis atos irregulares.

Este controle é comumente definido pelos autores de língua inglesa como accountability, termo também adotado no Brasil. A chamada accountability pode ser exercida de diversas formas, seja através dos próprios cidadãos durante 0 processo eleitoral em relação à administração pública (accountability vertical) ou por meio de instituições e agências que realizam o controle intraestatal da atuação (accountability horizontal), conforme a clássica divisão estabelecida por Guillermo O'Donnell (1998). No contexto em estudo, a fiscalização das atividades do Poder Executivo municipal é exercida, dentre outras maneiras, através do Poder Legislativo com o auxilio dos Tribunais de Contas dos Estados ou dos Tribunais de Contas dos Municípios, onde houver (artigo 31 da Constituição Federal de 1988).

Em relação ao município de São Paulo, particularmente, no que diz respeito à atuação internacional, deve-se destacar, no âmbito do Poder Legislativo, a existência da chamada "Comissão Extraordinária Permanente de Defesa de Direitos Humanos, Cidadania e Relações Internacionais", que possui entre suas atribuições acompanhar, sugerir e fiscalizar, junto ao Executivo, o desenvolvimento, a elaboração e a execução de convênios e projetos de cooperação internacional.

Portanto, o trabalho visa investigar se houve, entre os anos de 2013 e 2016, a prática de accountability da atuação internacional do município de São Paulo, implementada através de sua Secretaria de Relações Internacionais e Federativas, por parte do Poder Legislativo, através de sua "Comissão Extraordinária Permanente de Defesa de Direitos Humanos, Cidadania e Relações Internacionais". A pesquisa foi realizada através de duas fases em termos metodológicos, quais sejam, revisão bibliográfica e coleta de dados oriundos do próprio Poder Legislativo, obtidos por meio do "Serviço de Informação ao Cidadão" da Câmara Municipal da capital paulista, que possam evidenciar a existência da accountability desta atuação no período selecionado.

\section{A ATUAÇÃO INTERNACIONAL DE MUNICÍPIOS NO BRASIL}


Mônica Salomón (2011) afirma que a redemocratização e a descentralização ocorridas nos anos 1980 na América Latina favoreceram atividades internacionais por parte de governos não centrais. Neste período, sustenta a autora, houve o surgimento de estruturas institucionais de gestão das relações internacionais nos governos subnacionais brasileiros, fazendo com que nos dias atuais parte de governos estaduais e diversas prefeituras realizem ações internacionais.

Dois fatores foram importantes para o surgimento da atuação internacional de municípios na América Latina, quais sejam, o fim das ditaduras militares que governavam boa parte dos países no continente e a alteração do modelo econômico de substituição de importações para o modelo neoliberal (JAKOBSEN, 2009). Assim, o "processo de redemocratização foi articulado com a transição de modelo econômico e propôs um papel político e de gestor mais relevante para os governos locais ao mesmo tempo em que reduziu a capacidade financeira para que pudessem executá-lo." (JAKOBSEN, 2009, p. 24). Neste contexto, de acordo com o autor, este paradoxo leva provavelmente à seguinte consequência:

A inserção internacional das cidades latino-americanas a partir dos
anos 1990 guarda fortes aspectos solidários e cooperativos e foi
impulsionada por vários fatores. É provável que o paradoxo
mencionado tenha sido um dos determinantes para estimular os
governos locais a desenvolver ou ampliar as relações internacionais
municipais como forma de encontrar recursos e soluções técnicas para
enfrentar a crise da transição do modelo de desenvolvimento e as
consequências negativas da globalização. (JAKOBSEN, 2009, p. 25).

No Brasil de um modo geral pode-se dizer que a atuação internacional de municípios ganha força devido a uma série de fatores, entre eles o processo de redemocratização dos anos 1980, a descentralização política, a participação do país em processos de integração regional, bem como em razão dos processos de abertura e estabilidade econômica que marcaram os anos 1990 (FONSECA, 2013).

Wagner de Melo Romão (2009) ao analisar o contexto brasileiro realça o paradoxo dos governos locais. No caso brasileiro, a Constituição Federal de 1988 concede aos municípios o "status" de ente federado e ao mesmo tempo lhe delega novas e importantes responsabilidades em termos de políticas públicas, 
tais como educação e saúde. Esta situação complexa fez com que vários governos locais enviassem projetos de empréstimos ao exterior, especialmente, para o Banco Mundial e Banco Interamericano de Desenvolvimento (BID). Contudo, a atuação internacional dos entes subnacionais no Brasil também ganha força por outras questões, além da busca por financiamento externo, tal como adverte Wagner Romão:

\begin{abstract}
Entretanto, há muito mais na ação externa de cidades que a busca por financiamento direto. Para além da imposição de agendas no modo de execução das políticas públicas, as cidades têm se organizado para atuar firmemente nos processos de integração regional. As redes de cidades se transformaram, nos anos 1990 e na década atual, em ambientes irradiadores de poder, em que os governos locais buscam articular-se para pressionar os governos nacionais por uma maior e mais rápida integração. (ROMÃO, 2009, p. 51).
\end{abstract}

Na história brasileira encontramos alguns indícios de atuação internacional de entes subnacionais em situações pontuais, tais como nas questões migratórias durante o Império e em questões relacionadas à obtenção de financiamentos e investimentos pelos estados durante a República Velha (CASTELO BRANCO, 2008). As primeiras experiências institucionais em termos de atuação internacional de entes subnacionais só ocorreram no Brasil com a criação de escritórios de relações internacionais pelos estados do Rio de Janeiro em 1983 e do Rio Grande do Sul em 1987, além da criação de uma pasta governamental específica na cidade do Rio de Janeiro também em 1987, primeiro município brasileiro a institucionalizar a atividade internacional.

Contudo, a atuação internacional dos entes subnacionais no Brasil é anterior à sua institucionalização, já que a prática era exercida de maneira dispersa e não articulada pelos entes subnacionais, seja através de promoção comercial ou de cooperação por meio de acordos de cidades-irmãs (SALOMÓN, 2011). Estas atividades tiveram início em período anterior à promulgação da Constituição Federal de 1988, porém não se pode negar sua importância enquanto fator estimulador da atividade no Brasil.

A partir do ano de 2003, há significativo crescimento da institucionalização da atuação internacional com a criação de novas estruturas de gestão das relações internacionais nos governos subnacionais, especialmente, nas regiões Norte e Nordeste, período que coincide com a chegada do Partido dos 
Trabalhadores (PT) ao governo federal (SALOMÓN, 2011). A autora também destaca o fato de que os prefeitos das cidades pioneiras em termos de atuação internacional eram ou ainda são filiados ao Partido dos Trabalhadores (PT), o que está longe de ser apenas uma coincidência.

Os entes subnacionais brasileiros atuam internacionalmente em razão de diversas motivações, entre elas necessidades administrativas, políticas de desenvolvimento, interesses de grupos empresariais ou sociais e 0 fortalecimento da própria posição no cenário interno (VIGEVANI; PRADO, 2010). Ademais, os autores afirmam que estas motivações não constituem contraposições com as políticas feitas pelo Estado nacional. Assim, pode-se dizer que "[...] as unidades subnacionais brasileiras atuam externamente através do estabelecimento de acordos informais voltados para propósitos de promoção econômica, de desenvolvimento local, intercâmbio e cooperação internacional." (VIGEVANI; PRADO, 2010, p. 28).

Deve-se ressaltar que a atuação internacional é realizada de forma desvinculada da atuação direta do governo federal, tendo por objetivo o fortalecimento do desenvolvimento dos entes subnacionais sem prejudicar os fundamentos da política externa do Estado brasileiro (VIGEVANI; PRADO, 2010). A prática no Brasil ainda encontra-se em baixos níveis de institucionalidade, o que contribui para a sua limitação. Essa situação de baixa institucionalidade pode ser explicada pela ausência de reconhecimento da atuação na esfera jurídica, bem como devido à ausência ou pequena formalização de estruturas garantidoras da continuidade desta atuação internacional.

Estes mesmo autores (VIGEVANI; PRADO, 2010, p. 31) afirmam que os impedimentos relacionados à institucionalização da atuação internacional dos entes subnacionais no Brasil estão presentes em duas importantes esferas: no plano doméstico, onde a participação desses atores "[...] é regulada pelas Constituições Nacionais e na esfera internacional pelo não reconhecimento, no campo do direito internacional público, da personalidade jurídica dos governos subnacionais." Por fim, concluem que no Brasil há uma relação entre as atividades desenvolvidas internacionalmente pelos governos locais e o modo pelo qual o partido político do governante enfrenta a questão internacional. 
No Brasil há forte atuação internacional dos entes subnacionais em temas como turismo, cooperação técnica, investimentos, convênios tecnológicos, empréstimos, entre outros. Não há registro de atuação relacionada à temas que não guardem relação com questões locais. Por isso, pode-se dizer que na realidade brasileira não houve, até o presente momento, conflitos entre as esferas de governo nas questões de política exterior de competência do Estado nacional (VIGEVANI, 2006). Portanto, a atuação internacional dos entes subnacionais no Brasil não se encontra ligada à chamada protodiplomacia, que pode ser definida como a atuação internacional com viés separatista.

De qualquer forma, pode-se concluir que a atuação internacional dos entes subnacionais encontra-se em transformação. Inicialmente, houve um período de forte criação de secretarias e assessorias de relações internacionais nos municípios brasileiros, o que se explicaria em boa parte como uma resposta às novidades da área, tais como a Rede Mercocidades e o Programa URB-AL. Posteriormente, em um segundo período, a temática perde espaço na agenda política dos governos subnacionais brasileiros. Mesmo assim, "[...] a experiência acumulada, apesar de pequena, garantiu a criação de uma pequena burocracia de gestores locais especializados, que fazem com que temas internacionais sejam conduzidos com maior profissionalismo." (KLEIMAN; CEZÁRIO, 2011, p. 314). Esse profissionalismo, por sua vez, faz com que o tema da atuação internacional ganhe paulatinamente espaço na agenda política municipal brasileira.

Uma das possíveis formas de institucionalização desta atuação nos municípios é a criação de Secretarias de Relações Internacionais, sendo que a cidade de São Paulo pode ser considerado um município pioneiro nesse contexto, razão pela qual mostra-se de fundamental importante a apresentação de algumas considerações acerca da atuação internacional da capital paulista, especialmente, através de sua Secretaria Municipal de Relações Internacionais e Federativas.

\section{A SECRETARIA MUNICIPAL DE RELAÇÕES INTERNACIONAIS E FEDERATIVAS DE SÃO PAULO}


Logo após a promulgação da Constituição Federal de 1988 houve a promulgação da Lei Orgânica da capital paulista, sendo que nela há previsão para a prática da atuação internacional em seu artigo 4ํㅜㄹ cuja redação enuncia que "[...] o Município, respeitados os princípios do art. 4o da Constituição da República, manterá relações internacionais, através de convênios e outras formas de cooperação." (SÃO PAULO, 1989, grifo nosso). A inserção deste dispositivo na Lei Orgânica de São Paulo foi feita através do então vereador Pedro Dallari, hoje docente do curso de Relações Internacionais da Universidade de São Paulo (IRI-USP). De acordo com José Blanes Sala e Clara Maria Faria Santos (2009, p. 143), "[...] não existe no Brasil dispositivo similar apto a garantir com a mesma eficácia jurídica a atuação internacional dos poderes municipais."

A primeira experiência internacional em termos institucionais ocorreu na administração Luiza Erundina (PT) entre os anos de 1989 a 1992 com a criação da Coordenadoria de Relações Internacionais vinculada à Secretaria de Negócios Extraordinários. A pasta ficou sob a responsabilidade de Ladislau Dowbor. Nas administrações seguintes, especificamente, nas de Paulo Maluf (PDS) e Celso Pitta (PPB) houve a extinção da citada Coordenadoria, o que fez com que cada Secretaria Municipal desenvolvesse por conta própria projetos na esfera internacional. De qualquer forma, pode-se afirmar que "[...] nas duas gestões as questões relacionadas à interseção internacional centraram-se na busca de evidenciar o perfil empreendedor da cidade visando a promoção em busca do investimento privado internacional." (VIGEVANI; PRADO, 2010, p. 45).

Posteriormente, no ano de 2001, com o início da administração Marta Suplicy (PT) houve, por meio da Lei oㅜ 13.165/2001 (SÃO PAULO, 2001), a criação da Secretaria Municipal de Relações Internacionais (SMRI-SP), pasta com orçamento e estrutura próprios. Neste governo a Secretaria Municipal de Relações Internacionais teve como secretários Jorge Mattoso e Kjeld Jakobsen. A SMRI-SP, conforme artigo $1^{\circ}$ da Lei $13.165 / 2001$, tinha por objetivo primordial, no momento de sua criação, "coordenar convênios e projetos de cooperação internacional que envolvam a cidade de São Paulo, inserindo-a de forma ativa no cenário mundial, em razão de sua dimensão econômica, social e cultural."

De acordo com a Lei ㄲo 13.165/2001, a SMRI-SP foi criada com as seguintes atribuições: 1) assessorar o Chefe do Executivo em contatos 
internacionais com Governos e entidades públicas ou privadas; 2) estabelecer e manter relações e parcerias com organismos internacionais multilaterais, cidades-irmãs do Município de São Paulo, entidades voltadas à organização de cidades, organizações não governamentais internacionais, representantes diplomáticos de Governos, representantes de trabalhadores e de empresários internacionais, empresas internacionais estabelecidas ou não no Município de São Paulo e outras entidades afins; 3) fornecer suporte técnico aos órgãos da Administração Direta e Indireta do Município de São Paulo em contatos internacionais, bem como no desenvolvimento e elaboração de convênios e projetos de cooperação internacional. No momento de sua criação a SMRI-SP era composta pelo Gabinete do Secretário, integrado por Coordenadores Gerais, para gerenciar os projetos e convênios internacionais, Assessores Técnicos e Assistência Administrativa (artigo 3o da Lei oㅜ 13.165/2001).

No ano de 2005, José Serra (PSDB) assume a Prefeitura de São Paulo adotando um discurso de contenção de gastos e despesas, o que previa, inclusive, a redução ou eliminação de algumas secretarias. A SMRI-SP seria uma das pastas governamentais a ser extinta pela administração. Esse fato fez com que o ex-secretário Kjeld Jakobsen escrevesse um artigo onde defendeu a importância da SMRI-SP, elencando todos os projetos já realizados. Então, José Serra (PSDB) acabou por manter a SMRI-SP, designando como secretária a diplomata Helena Maria Gasparian, além de ter criado a função de secretárioadjunto, ocupado inicialmente por Christian Lohbauer em 2005 e Adriano Zerbini em 2006. No final de 2006, José Serra se candidata ao cargo de governador de São Paulo, tendo sido eleito. Gilberto Kassab (DEM) assume a Prefeitura de São Paulo, nomeando como Secretário Municipal de Relações Internacionais Alfredo Cotait Neto, cargo que ocupou até o término do segundo mandato de Gillberto Kassab em 2012.

Desde o ano de 2013, com o início da administração Fernando Haddad (PT) e a promulgação da Lei Municipal oㅜ 15.764/2013 (SÃO PAULO, 2013), o órgão passou a se chamar Secretaria Municipal de Relações Internacionais e Federativas (SMRIF-SP), tendo inicialmente como secretário Leonardo Osvaldo Barchini Rosa e, a partir de 2015, Vicente Trevas. Consta do artigo 223 da Lei $15.764 / 2013$ que a pasta possui por objetivo principal a promoção e coordenação 
de "[...] ações conjuntas e de cooperação com a União, os Estados, os Municípios, em especial, os da Região Metropolitana da Grande São Paulo e entes e organizações internacionais e estrangeiros." (SÃO PAULO, 2013, grifo nosso). Ademais, de acordo com o artigo 224 da Lei 15.764/2013, a Secretaria Municipal de Relações Internacionais e Federativas de São Paulo deve assessorar o Prefeito e os órgãos da administração direta e indireta do município em diversos outros casos:

Art. 224. Compete à Secretaria Municipal de Relações Internacionais e Federativas assessorar o Prefeito e os órgãos da Administração Direta e Indireta do Município:

I - nas relações e no desenvolvimento de ações conjuntas e de cooperação com os demais entes da Federação;

II - nos assuntos relacionados à Região Metropolitana da Grande São Paulo e seus órgãos de gestão;

III - nas relações de cooperação com instituições e centros de estudos sobre federalismo;

IV - nas relações com associações e entidades de representação de Municípios;

V - nas relações e no desenvolvimento de ações conjuntas e de cooperação com governos estrangeiros e seus representantes diplomáticos e consulares;

VI - nas relações e no desenvolvimento de ações conjuntas e de cooperação com entidades públicas e privadas de caráter internacional;

VII - nas relações e parcerias com organismos e fóruns internacionais multilaterais, em especial, com redes de cidades, cidades-irmãs do Município de São Paulo e no âmbito do Mercado Comum do Sul MERCOSUL, da União de Nações Sul-Americanas - UNASUL e a Comunidade dos Estados Latinoamericanos e Caribenhos - CELAC; VIII - na organização e coordenação de eventos de relevância nacional e internacional;

IX - na identificação de projetos, ações e boas práticas nacionais e internacionais de interesse do Município. (SÃO PAULO, 2013).

Atualmente a estrutura administrativa da Secretaria é composta pelo Gabinete do Secretário, Assessoria Especial de Relações Metropolitanas, Coordenadoria de Relações Federativas, Assessoria Especial para Assuntos Internacionais, Coordenação de Cooperação Internacional e Rede de Cidades, Coordenação de Projetos Especiais, Coordenadoria de Assessoria Internacional e Cooperação Bilateral e Supervisão de Administração e Finanças. Por fim, a Lei no 15.764/2013 enuncia que a Secretaria poderá, no exercício de suas atribuições, manter escritório permanente no Distrito Federal.

A atuação da SMRIF-SP se dá por meio de acordos de cooperação bilateral e multilateral, participação em redes de cidades e em eventos internacionais. Os 
acordos de cooperação bilateral são firmados "[...] quando há interesse de ambas as partes em estreitar laços políticos e culturais, a fim de viabilizar projetos e iniciativas em parceria." (SÃO PAULO, [2015], grifo nosso). De acordo com o site da SMRIF-SP foram firmados até o presente momento quinze acordos de cooperação bilateral envolvendo nove países (Argentina, China, Cuba, França, Inglaterra, Itália, Países Baixos, Suíça e Estados Unidos).

Há também na categoria dos acordos de cooperação bilateral os chamados acordos bilaterais de Cidades-Irmãs, que "[...] podem propiciar troca de conhecimentos sobre políticas públicas e projetos em diversas áreas como programas de saúde, políticas culturais, e outros temas de interesse mútuo das cidades." (SÃO PAULO, [2015], grifo nosso). De acordo com a própria Secretaria de Relações Internacionais, estes representam "o substrato formal e legal para o estabelecimento de eventuais acordos de cooperação técnica, programas de intercâmbio e desenvolvimento econômico, e atendimento à comunidade descendente do país ou região da cidade irmã." (SÃO PAULO, [2015], grifo nosso). Os acordos bilaterais de Cidades-Irmãs estão consolidados juridicamente por meio da Lei Municipal no 14.471/2007 (SÃO PAULO, 2007). De acordo com o ex-secretário da Secretaria Municipal de Relações Internacionais e Federativas de São Paulo Leonardo Barchini, o grande desafio do órgão "[...] é o de avaliar os acordos já existentes e recuperar agendas com as cidades com as quais se busca maior aproximação, fazendo uso de acordos bilaterais mais específicos e pautados em ações concretas." (ROSA, 2014, p. $63)$.

Os acordos de cooperação multilateral são instrumentos firmados no âmbito de organizações internacionais. No caso do município de São Paulo já foram firmados acordos com a Organização das Nações Unidas (ONU), Banco Interamericano de Desenvolvimento (BID), Organização dos Estados Iberoamericanos (OEI), Comissão Econômica para América Latina e Caribe (CEPAL) e Organização Internacional do Trabalho (OIT).

Há ainda a participação internacional por meio das chamadas "redes de cidades", tendo o município de São Paulo participado da Cidades e Governos Locais Unidos (CGLU), Mercocidades, Associação Internacional de Cidades Educadoras (AICE), Grupo C40 de Grandes Cidades para a Liderança Climática, 
Associação Mundial de Grandes Metrópoles (Metropolis) e a União de Cidades Capitais lberoamericanas (UCCl).

A atuação da SMRIF-SP se dá também por meio de missões institucionais e técnicas. As missões institucionais realizadas pela Secretaria de Relações Internacionais "[...] têm como objetivo fazer a representação da cidade em eventos e fóruns internacionais, buscando reposicioná-la no cenário internacional e imprimir uma nova narrativa sobre a cidade de São Paulo junto aos interlocutores externos." (ROSA, 2014, p. 64). As chamadas missões técnicas, por sua vez, "[...] têm como principal função o reconhecimento de melhores práticas urbanas, a fim de requalificar a gestão pública municipal." (ROSA, 2014, p. 64). Por fim, ainda no que diz respeito às missões técnicas, também deve ser observado que estas são realizadas de maneira articulada com os demais órgãos da administração pública municipal.

Como se vê, a cidade de São Paulo pode ser considerada pioneira e referência em termos de atuação internacional. Portanto, tendo em vista que a atuação internacional constitui uma importante alternativa em termos de formulação e implementação de políticas públicas, deve-se investigar se há algum tipo de controle ou fiscalização no que diz respeito à esta atuação. Tal controle é comumente definido como accountability, conceito apresentado nas linhas abaixo.

\section{REVISITANDO O CONCEITO DE ACCOUNTABILITY}

O debate atual da accountability remete aos acontecimentos ocorridos a partir da década de noventa, especificamente, a chamada Terceira Onda de democratização e as reflexões teóricas relacionadas à consolidação da democracia (MOTA, 2006). No que se refere à América Latina muitos países após anos de domínio de governos autoritários passaram a realizar eleições livres, evidenciando a preocupação com a consolidação de instituições representativas estáveis em jovens democracias.

A década de 1990 na América Latina foi palco do surgimento de novos referenciais teóricos que visavam analisar a relação entre sociedade civil e Estado, dando-se ênfase à participação do cidadão nos processos políticos. 
Houve nestas circunstâncias uma grande preocupação em relação aos mecanismos colocados à disposição do cidadão para participar de modo mais efetivo do processo político, gerando demandas em termos de transparência da atuação pública. É exatamente neste contexto que se situa a discussão relacionada à accountability.

Guillermo O'Donnell (1998) pode ser considerado um dos autores pioneiros e mais influentes no debate da accountability. $O$ autor apresenta uma distinção entre duas espécies de accountability: a vertical e a horizontal. A primeira seria implementada, fundamentalmente, através das eleições, onde os eleitores realizam o controle da atuação pública através de seus votos, "premiando" aqueles que exerceram corretamente sua função e "punindo" os que agiram em sentido contrário. A chamada accountability horizontal, por sua vez, traduz a ideia da existência de órgãos estatais que detém poder e capacidade para "realizar ações, que vão desde a supervisão de rotina a sanções legais ou até o impeachment contra ações ou omissões de outros agentes ou agências do Estado que possam ser qualificadas como delituosas." (O'DONNELL, 1998, p. 40).

O interesse pelo tema da accountability horizontal por parte de Guillermo O'Donnell surge em razão da sua suposta ausência, especificamente, em países da América Latina, conforme ressaltado pelo próprio autor. De qualquer forma, a efetividade dos mecanismos de controle intraestatal exige que as instituições responsáveis pela accountability horizontal não atuem isoladamente, mas sim por meio de redes de agências e instituições correlatas. No pensamento de Guillermo O'Donnell, a ideia básica em termos de accountability horizontal é a de prevenção, além de punição caso seja necessário. $O$ autor também ressalta a importância da autonomia por parte das agências responsáveis pelo controle intraestatal, sendo que essa autonomia pressupõe o estabelecimento de fronteiras quanto à atuação, além de reconhecimento e respeito por parte de outros atores relevantes.

Outra questão importante apresentada por O'Donnell consiste na, por ele assim denominada, violação da accountability horizontal, que pode ocorrer em duas situações: quando há usurpação ilegal por uma agência estatal da autoridade de outra e quando uma autoridade pública obtém, para si ou para 
outros membros da agência, vantagens ilícitas. A primeira situação é denominada por O'Donnell de usurpação e a segunda de corrupção. O autor assevera que a usurpação se mostra mais perigosa do que a própria corrupção, já que a primeira simplesmente liquidaria a poliarquia e a segunda, não obstante ocasionar a sua deterioração, não necessariamente a eliminaria. O objetivo principal da accountability seria, portanto, evitar ou minimizar os resultados decorrentes de ações e omissões consideradas delituosas.

Outros autores da literatura estrangeira também apresentaram considerações importantes acerca da accountability, inclusive tecendo críticas ao pensamento de Guillermo O'Donnell. Neste sentido, podemos citar Adam Przeworski (1999) e Schedler (1999).

Przeworski (1999) rebate a afirmação de O'Donnell de que a accountability horizontal seria inexistente nas democracias latino-americanas, pois em muitos países da América Latina encontramos diversas instituições (Poder Legislativo, agências de fiscalização, promotorias públicas, etc) em plena atuação no que se refere ao controle sobre a atuação do Poder Executivo.

Schedler (1999), por sua vez, apresenta críticas à classificação de O'Donnell (accountability horizontal e vertical), pois a vertical supostamente descreveria uma relação estabelecida entre desiguais, onde um ator dotado de maior poder manteria outro menos poderoso submetido à accountability. Em relação à accountability horizontal, Schedler afirma que esta concepção introduzida por O'Donnell traduz a ideia de que os sujeitos envolvidos possuiriam o mesmo nível de poder, sendo que a mensuração deste poder nas circunstâncias reais se mostra impossível. Além das críticas em relação à classificação proposta por O’Donnell, Schedler também aborda as chamadas dimensões da accountability, pois trata-se de um conceito pluridimensional. Assim, a accountability apresenta três dimensões: informação, justificação e punição. Essas dimensões estão intimamente ligadas às características que constituem a accountability, quais sejam, answerability (representa a necessidade de se dar explicações) e enforcement (poder de coação legal).

No Brasil a discussão referente à accountability ganha força com a publicação do trabalho de Ana Maria Campos (1990). O artigo apesar de publicado no ano de 1990 foi escrito em 1987, um ano antes da promulgação da 
Constituição Federal. Logo, o contexto existente na época da confecção do trabalho ainda era o de transição de um governo autoritário para o regime democrático. De qualquer forma, Ana Maria Campos questiona se seria possível a tradução do termo accountability para o português, ressaltando que tradução não seria apenas a inexistência de uma palavra correspondente em nossa língua, mas também se seria possível a incorporação de valores relativos à accountability no Brasil. De acordo com Ana Maria Campos, no momento em que foi escrito $o$ artigo, notava-se na dimensão horizontal da accountability uma certa supremacia do Poder Executivo em relação aos demais poderes, fruto de anos de autoritarismo político, sendo que no Poder Legislativo os parlamentares "parecem só preocupados com seus interesses pessoais e as conveniências de seus parentes e amigos." (CAMPOS, 1990, p.10). Ademais, o Poder Judiciário se mostrava ainda dependente do Poder Executivo, inclusive no que diz respeito aos recursos financeiros, além de inexistir uma sólida organização por parte da sociedade civil, fazendo com que pouco espaço houvesse para 0 desenvolvimento e aperfeiçoamento de instituições de accountability horizontal.

Ana Maria Campos ao afirmar que as circunstâncias brasileiras da época não eram favoráveis a criação de uma administração pública transparente e compatível com as expectativas políticas formula alguns requisitos para o desenvolvimento da accountability no Brasil, quais sejam, organização da sociedade civil, descentralização do aparato governamental visando a diluição da concentração de poder como forma de se possibilitar a atuação das agências de accountability horizontal e o surgimento de novos valores sociais em substituição aos tradicionais (CAMPOS, 1990, p. 18).

Posteriormente, José Antônio Gomes de Pinho e Ana Rita Silva Sacramento (2009) retomam as análises de Ana Maria Campos ao discutirem possíveis mudanças no contexto brasileiro em direção à accountability. Os autores sustentam que a mera reformulação de instituições visando a ampliação dos mecanismos de controle político não é suficiente para o fortalecimento de uma cultura de accountability na América Latina. É necessário o surgimento de novos valores sociais para tanto, como forma de se combater antigas práticas relacionadas com as tradições oligárquicas da história latinoamericana. 
Os autores além de ressaltarem a importância do surgimento de novos valores também dão ênfase ao surgimento de novas organizações, tais como Instituto Ethos e o Movimento de Combate à Corrupção Eleitoral. Pinho e Sacramento (2009) também apontam o caráter inovador da Constituição Federal de 1988 que reconhece o município enquanto ente federativo. De acordo com os autores, a partir da promulgação da Constituição Federal de 1988 várias atribuições foram transferidas ao poder local, transferência de responsabilidades que possibilita um maior contato do cidadão com as instâncias decisórias e o processo político de um modo geral, gerando o fortalecimento do regime democrático e a maior visibilidade do representante em relação ao representado.

$\mathrm{Na}$ literatura brasileira também encontramos outros relevantes trabalhos que tratam da accountability. A título de exemplo, podemos citar a tese de doutorado de Ana Carolina Yoshida de Andrade Mota (2006) que abordou a utilização da denominada ação popular como instrumento de accountability. A tese de doutorado mostra-se de fundamental importância no que se refere à revisão da bibliografia sobre accountability, fazendo com que a autora contribua com as pesquisas já produzidas ao apresentar o que seria um conceito mínimo de accountability:

Trata-se de um mecanismo de controle de poder com a natureza
jurídica de uma relação obrigacional objetiva extra-contratual (isto é,
legal) que coage os agentes encarregados da administração de
interesses públicos (basta que o agente tenha múnus público) a
explicar seus atos discricionários, tornando públicas as suas
motivações, quando provocados institucionalmente, sob pena punição
legal (previsão de punição=sanção em estado potencial). (MOTA,
2006, p. 58).

No contexto em estudo, conforme afirmado anteriormente, a fiscalização das atividades do Poder Executivo municipal é exercida, dentre outras maneiras, através do Poder Legislativo. Em relação ao município de São Paulo, particularmente, no que diz respeito à atuação internacional, há, no âmbito do Poder Legislativo, a chamada "Comissão Extraordinária Permanente de Defesa de Direitos Humanos, Cidadania e Relações Internacionais", que possui entre suas atribuições acompanhar, sugerir e fiscalizar, junto ao Executivo, o desenvolvimento, a elaboração e a execução de convênios e projetos de cooperação internacional. No próximo tópico será investigado tal mecanismo de 
accountability no contexto da atuação internacional do município de São Paulo através de sua Secretaria Municipal de Relações Internacionais e Federativas.

\section{A (IN)EXISTÊNCIA DE ACCOUNTABILITY DA ATUAÇÃO INTERNACIONAL DO MUNICÍPIO DE SÃO PAULO}

A atuação da Câmara Municipal de São Paulo se dá de diversas formas, entre elas, por meio das Comissões. De acordo com o artigo 38 do Regimento Interno as Comissões são classificadas em permanentes, extraordinárias e temporárias. As primeiras têm caráter técnico-legislativo e possuem como finalidade apreciar os assuntos ou proposições submetidas ao seu exame, bem como exercer as demais atribuições previstas na Lei Orgânica do Município. As comissões extraordinárias também apresentam caráter técnico-legislativo e têm a competência de promover estudos e debates, avaliar e promover políticas públicas nas respectivas áreas de atuação. Por fim, as comissões temporárias são as criadas para assunto específico, que se extinguem quando atingida a sua finalidade ou expirado seu prazo de duração (SÃO PAULO, 1991).

O artigo 46 do Regimento Interno da Câmara Municipal de São Paulo apresenta as competências genéricas das comissões, apresentando um extenso rol. Dentre tais competências pode-se destacar as seguintes: estudar proposições e outras matérias submetidas ao seu exame; promover estudos, pesquisas e investigações sobre assuntos de interesse público; realizar audiências públicas; convocar os Secretários Municipais, os responsáveis pela administração direta ou indireta e os Conselheiros do Tribunal de Contas do Município, para prestar informações sobre assuntos inerentes às suas atribuições; receber petições, reclamações, representações ou queixas de associações e entidades comunitárias ou de qualquer pessoa contra atos e omissões de autoridades municipais ou entidades públicas; solicitar ao Prefeito informações sobre assuntos inerentes à administração, dentro da competência da Comissão; fiscalizar, inclusive efetuando diligências, vistorias e levantamentos "in loco", os atos da administração direta e indireta, nos termos da legislação pertinente, em especial para verificar a regularidade, a eficiência e a eficácia dos seus órgãos no cumprimento dos objetivos institucionais, 
recorrendo ao auxilio do Tribunal de Contas do Município, sempre que necessário; solicitar informações ou depoimentos de autoridades ou cidadãos; requisitar dos responsáveis a exibição de documentos e a prestação dos esclarecimentos necessários (SÃO PAULO, 1991).

Atualmente, a Câmara Municipal de São Paulo apresenta sete comissões permanentes: Comissão de Constituição e Justiça e Legislação Participativa; Comissão de Finanças e Orçamento; Comissão de Política Urbana, Metropolitana e Meio Ambiente; Comissão de Administração Pública; Comissão de Trânsito, Transporte, Atividade Econômica, Turismo, Lazer e Gastronomia; Comissão de Educação, Cultura, Esportes e Lazer; Comissão de Saúde, Promoção Social, Trabalho e Mulher. Em relação às comissões extraordinárias permanentes são atualmente cinco: Comissão Extraordinária Permanente de Defesa dos Direitos Humanos, Cidadania e Relações Internacionais; Comissão Extraordinária Permanente de Defesa dos Direitos da Criança, do Adolescente e da Juventude; Comissão Extraordinária Permanente do ldoso e da Assistência Social; Comissão Extraordinária Permanente de Segurança Pública e a Comissão Extraordinária Permanente de Meio Ambiente. Por fim, as comissões temporárias são as denominadas Comissões Parlamentares de Inquérito (CPIs) e as Comissões de Estudo (SÃO PAULO, 1991).

De acordo com o artigo 38, parágrafo $2^{\circ}$, do Regimento Interno a Comissão Extraordinária Permanente de Defesa dos Direitos Humanos, Cidadania e Relações Internacionais apresentam nove membros, bem como possuem as seguintes competências específicas elencadas no artigo 47 , inciso VIII, também do Regimento Interno: receber, avaliar e proceder à investigação de denúncias relativas às ameaças ou violações de direitos humanos; fiscalizar e acompanhar programas governamentais relativos à proteção dos direitos humanos; colaborar com entidades não governamentais, nacionais e internacionais, que atuem na defesa dos direitos humanos; pesquisar e estudar a situação da cidadania e dos direitos humanos no Município de São Paulo; estabelecer e manter relações e parcerias com organismos multilaterais, organizações não governamentais internacionais, fundações, representantes diplomáticos, empresas internacionais, cidades-irmãs do Município de São Paulo e outras entidades afins; acompanhar, sugerir e fiscalizar, junto ao Executivo, o desenvolvimento, a 
elaboração e a execução de convênios e projetos de cooperação internacional e assessorar a Câmara Municipal e contatos internacionais com Governos, entidades públicas ou privadas, bem como nos contatos com as delegações estrangeiras (SÃO PAULO, 1991).

No ano de 2013 compuseram a Comissão Extraordinária Permanente de Defesa dos Direitos Humanos, Cidadania e Relações Internacionais os seguintes vereadores: Juliana Cardoso (Presidente da Comissão), Laércio Benko (VicePresidente da Comissão), Coronel Camilo, Alfredinho, Ari Friedenbach, Patrícia Bezerra, Rubens Calvo, Ricardo Young e Orlando Silva. No ano de 2014 a Comissão apresentou a seguinte composição: Ari Friedenbach (Presidente da Comissão), Juliana Cardoso (Vice-Presidente da Comissão), Jair Tatto, Coronel Camilo e Rubens Calvo. Posteriormente, no ano de 2015, a Comissão apresentou a seguinte composição: Laércio Benko (Presidente da Comissão), Netinho de Paula (Vice-Presidente da Comissão), Ari Friedenbach, Alfredinho, José Police Neto, Juliana Cardoso, Rubens Calvo e Patrícia Bezerra. Por fim, no último ano da legislatura, em 2016, a Comissão foi composta pelos vereadores Juliana Cardoso (Presidente da Comissão), Patrícia Bezerra (Vice-Presidente da Comissão), Ari Friedenbach, Alfredinho, José Police Neto, Jamil Murad, Rubens Calvo e Rodolfo Despachante (protocolo e-SIC 17225).

No que diz respeito às reuniões da Comissão no ano de 2013 foram designados quinze encontros divididos da seguinte forma: uma sessão de instalação, quatro sessões ordinárias, cinco reuniões de trabalho, uma sessão extraordinária, uma conferência e três audiências públicas. Dos quinze encontros designados para o ano de 2013 nenhum apresentava a atuação internacional de São Paulo como tema, conformem constata-se da tabela abaixo (protocolo e-SIC 18427). 


\begin{tabular}{|c|c|c|}
\hline \multicolumn{3}{|r|}{ Comissão de Direitos Humanos - Pautas 2013} \\
\hline REUNIÃO & DATA & PAUTA \\
\hline Instalação & $09 / 05 / 2013$ & Eleição de presidente e vice \\
\hline Ordinária & $23 / 05 / 2013$ & Deliberação dos temas das próximas reuniões da Comissão de Direitos Humanos \\
\hline Trabalho & $06 / 06 / 2013$ & Operação Inverno e Moradores em Situação de Rua \\
\hline Ordinária & $20 / 06 / 2013$ & $\begin{array}{l}\text { Oitiva do Representante do Sindicato dos Jornalistas, Jornalistas e Repórteres Fotográficos, Movimento Passe Livre e Representante } \\
\text { da Policia Militar do Estado de São Paulo, sobre as agressões sofridas pelos manifestantes e profissionais de jornalismo, no exercício } \\
\text { regular de suas funções, ocorridas no dia } 13 \text { de junho na Manifestação para Redução da Tarifa dos Transportes Públicos }\end{array}$ \\
\hline Audiência Pública & $26 / 06 / 2013$ & Discutir a polêmica a respeito da Redução da Maioridade Penal \\
\hline Ordinária & $29 / 08 / 2013$ & $\begin{array}{l}\text { Aprovação de Novos Requerimentos;Agendamento das Visitas Externas: CAPE (Central de Atendimento Permanente e de } \\
\text { Emergência) e Centro de Acolhida }\end{array}$ \\
\hline Ordinária & $12 / 09 / 2013$ & Atuação da Fundação Casa no Município de São Paulo \\
\hline Trabalho & $26 / 09 / 2013$ & Aprovação de Requerimentos e outras Deliberações \\
\hline Trabalho & $10 / 10 / 2013$ & Apuração de Denúncias de Agressão contra os Moradores de Rua \\
\hline Trabalho & $24 / 10 / 2013$ & Apuração de Denúncias de Agressão contra os Moradores de Rua \\
\hline Audiência Pública & $29 / 10 / 2013$ & Comissão de Direitos Humanos. Violência Institucional contra a Juventude Negra, Pobre e Periférica Paulistana \\
\hline Extraordinária & $14 / 11 / 2013$ & Aprovação de Requerimentos e Diálogos e Perspectivas das Ações da Coordenação de Políticas LGBT \\
\hline Trabalho & $05 / 12 / 2013$ & Apresentação das atividades desenvolvidas em 2013 pelos membros no que diz respeito ao tema da Comissão \\
\hline Conferência & $11 / 12 / 2013$ & Conferência Municipal de Direitos Humanos \\
\hline Audiência Pública & $12 / 12 / 2013$ & $\begin{array}{l}\text { Conjunta com Comissão de Educação: Debater o projeto Território Funk, recentemente entregue ao Prefeito pela Liga do Funk, que } \\
\text { além de propor ações de apoio à manifestação cultural, propõe a criação de oficinas, palestras e ações sociais, usando o estilo musical } \\
\text { como mote }\end{array}$ \\
\hline
\end{tabular}

Fonte: Câmara Municipal de São Paulo (protocolo e-SIC 18427)

A Comissão no ano de 2014 designou sete encontros, sendo uma sessão de instalação, cinco reuniões de trabalho e uma sessão extraordinária (29 de outubro), não sendo realizada nenhuma audiência pública nesse período. Dos sete encontros designados para o ano de 2014 nenhum deles apresentava a atuação internacional de São Paulo como tema, conforme tabela abaixo (protocolo e-SIC 18427).

\begin{tabular}{|c|c|l|}
\hline \multicolumn{3}{|c|}{ Comissão de Direitos Humanos - Pautas 2014 } \\
\hline REUNIÃO & DATA & \multicolumn{1}{|c|}{ PAUTA } \\
\hline Instalação & $24 / 04 / 2014$ & Eleição do presidente e vice-presidente \\
\hline Trabalho & $15 / 05 / 2014$ & Apresentação da programação para o primeiro semestre e avaliação de documentos recebidos \\
\hline Trabalho & $22 / 05 / 2014$ & Explanação da situação dos haitianos no município de São Paulo \\
\hline Trabalho & $09 / 06 / 2014$ & Violação dos Direitos Humanos dos Moradores de Rua durante a Copa do Mundo \\
\hline Trabalho & $11 / 09 / 2014$ & Elaboração da pauta para as reuniões do 20 semestre \\
\hline Extraordinária & $29 / 10 / 2014$ & Apoio e fiscalização do governo municipal às ONGs que atuam com população carente \\
\hline Trabalho & $10 / 12 / 2014$ & Atendimento a mulheres vítimas de violência sexual \\
\hline
\end{tabular}

Fonte: Câmara Municipal de São Paulo (protocolo e-SIC 18427)

No ano de 2015 a Comissão designou treze encontros divididos da seguinte forma: uma sessão de instalação, nove reuniões de trabalho, três sessões ordinárias e uma audiência pública. Novamente nenhuma das reuniões designadas apresentou como temática a atuação internacional do município de São Paulo, conforme constata-se através da tabela abaixo (protocolo e-SIC 18427). 


\begin{tabular}{|c|c|l|}
\hline \multicolumn{3}{|c|}{ Comissão de Direitos Humanos - Pautas 2015 } \\
\hline REUNIÃO & DATA & \multicolumn{1}{|c|}{ PAUTA } \\
\hline Instalação & $31 / 03 / 2015$ & Eleição de presidente e vice \\
\hline Trabalho & $16 / 04 / 2015$ & Planejamento para 2015 \\
\hline Ordinária & $30 / 04 / 2015$ & Eleição para nova Presidência \\
\hline Trabalho & $14 / 05 / 2016$ & Definição de audiências públicas para tratar de temas referentes às religiões de matriz africanas \\
\hline Trabalho & $28 / 05 / 2015$ & $\begin{array}{l}\text { Discussão sobre a reintegração de posse da área indígena do Jaraguá; discussão de problemas e } \\
\text { soluções da comunidade LGBT - com a presença do Coordenador de Políticas para LGBT, o Sr. }\end{array}$ \\
\hline Trabalho & $11 / 06 / 2015$ & Definição de temas para as próximas reuniões \\
\hline Trabalho & $25 / 06 / 2015$ & Pessoas Desaparecidas \\
\hline Trabalho & $06 / 08 / 2015$ & programação para o segundo semestre \\
\hline Trabalho & $20 / 08 / 2015$ & programação para o segundo semestre \\
\hline Ordinária & $17 / 09 / 2015$ & Redução da maioridade penal \\
\hline Trabalho & $26 / 11 / 2015$ & Atentados na França não podem reforçar intolerância religiosa \\
\hline Audiência Pública & $30 / 11 / 2015$ & PL 409/2014 - Instituição do hip hop como manifestação cultural na cidade de São Paulo \\
\hline Ordinária & $10 / 12 / 2015$ & Comemoração do Dia Internacional dos Direitos Humanos \\
\hline
\end{tabular}

Fonte: Câmara Municipal de São Paulo (protocolo e-SIC 18427)

Por fim, no ano de 2016, último da legislatura em estudo, a Comissão designou cinco encontros divididos da seguinte forma: quatro reuniões de trabalho e uma sessão ordinária. Nesse período apenas uma reunião (24 de março) tratou de assunto correlato à atuação internacional de São Paulo, qual seja, a relação da capital paulista com a comunidade chinesa (protocolo e-SIC 18427).

\begin{tabular}{|c|c|l|}
\hline \multicolumn{3}{|c|}{ Comissão de Direitos Humanos - Pautas 2016 } \\
\hline REUNIÃO & DATA & \multicolumn{1}{c|}{ PAUTA } \\
\hline Trabalho & $18 / 02 / 2016$ & liberdade de culto \\
\hline Trabalho & $24 / 03 / 2016$ & relação da cidade de São Paulo com a comunidade chinesa \\
\hline Trabalho & $05 / 05 / 2016$ & Condições da população indígena na Cidade de São Paulo \\
\hline Trabalho & $02 / 06 / 2016$ & Mães e pais na luta pela educação \\
\hline Ordinária & $16 / 11 / 2016$ & Eleição do Presidente e Vice-presidente \\
\hline
\end{tabular}

Fonte: Câmara Municipal de São Paulo (protocolo e-SIC 18427)

Portanto, na legislatura 2013-2016 a Comissão Extraordinária Permanente de Defesa dos Direitos Humanos, Cidadania e Relações Internacionais da Câmara Municipal de São Paulo designou quarenta e um encontros, sendo estes divididos da seguinte forma: três sessões de instalação, oito sessões ordinárias, vinte e três reuniões de trabalho, duas sessões extraordinárias, quatro audiências públicas e uma conferência. Destas quarenta e uma atividades apenas uma apresentou relação com a atividade internacional de São Paulo ao tratar do relacionamento da capital paulista com a comunidade chinesa (protocolo e-SIC 18427).

No período estudado a Comissão Extraordinária Permanente de Defesa dos Direitos Humanos, Cidadania e Relações Internacionais recebeu treze 
ofícios, sendo que nenhum deles tratava de assuntos relacionados à atuação internacional de São Paulo. Ademais, a mesma Comissão, também na mesma legislatura 2013 a 2016, encaminhou cento e dezoito ofícios, sendo que cem deles constituem convites para autoridades e personalidades participarem de reuniões e audiências públicas. Não foram encaminhados nesse período ofícios à Secretaria Municipal de Relações Internacionais de São Paulo solicitando informações ou esclarecimentos a respeito das políticas públicas desenvolvidas por meio da cooperação internacional (protocolo e-SIC 18427).

Em relação à atuação internacional de São Paulo foram encontrados sete ofícios (números 01/2015, 02/2015, 03/2015, 04/2015, 05/2015, 06/2015 e 07/2015) enviados ao Vice-Cônsul Geral da República Popular da China em São Paulo, ao Presidente do Conselho Fiscal da Associação Chinesa do Brasil, ao Presidente da Câmara de Comércio Brasil-China, ao Vice-Presidente da Câmara de Comércio Brasil-China, ao Secretário Geral da Câmara de Comércio BrasilChina, ao Presidente do Conselho Fiscal da Associação Chinesa Wenzhou do Brasil e ao Presidente da Associação Geral Minnan da América do Sul, todos estes ofícios tinha como objetivo convidar as autoridades e personalidades indicadas para a reunião que trataria da relação da cidade de São Paulo com a comunidade chinesa em 24 de março de 2016, sendo que o Secretário Municipal de Relações Internacionais de São Paulo não foi convidado para tal reunião (protocolo e-SIC 18427).

Finalmente, no que diz respeito à atuação da Comissão Extraordinária Permanente de Defesa dos Direitos Humanos, Cidadania e Relações Internacionais no período de 2013 a 2016, a própria Secretaria Municipal de Relações Internacionais e Federativas de São Paulo informou que na legislatura em estudo não recebeu nenhuma visita por parte dos membros da Comissão, bem como confirmou que não recebeu qualquer ofício oriundo da mesma Comissão (protocolo e-SIC 20187).

Portanto, os dados obtidos junto ao Poder Público evidenciam que entre os anos de 2013 e 2016 a Comissão Extraordinária Permanente de Defesa dos Direitos Humanos, Cidadania e Relações Internacionais não realizou qualquer controle sobre a atuação internacional da capital paulista, não obstante ser esta 
uma de suas atribuições previstas no próprio Regimento Interno da Câmara Municipal de São Paulo.

\section{CONSIDERAÇÕES FINAIS}

A atuação internacional dos municípios no Brasil hoje é uma realidade, ainda que restrita às cidades de grande e médio porte. A Constituição Federal de 1988 fez com que o município se tornasse um importante agente indutor e executor de políticas públicas, fazendo com que muitos passassem a atuar internacional como forma de suprir suas demandas, já que por diversas vezes os problemas sociais exigem soluções criativas e diversificadas em seu enfrentamento, especialmente, em razão de graves problemas financeiros que acometem os municípios no Brasil.

O município de São Paulo é considerado pioneiro em termos de atuação internacional, pois encontramos registros desta prática no governo Luiza Erundina. A atuação internacional na capital paulista se institucionalizou no governo Marta Suplicy em 2001 com a criação da Secretaria Municipal de Relações Internacionais, órgão existente até os dias atuais, só que desde 2013 denominado de Secretaria Municipal de Relações Internacionais e Federativas de São Paulo. Trata-se de uma importante pasta na administração pública municipal que atua de diversas formas, estabelecendo parcerias com outros municípios no exterior e também atuando de forma articulada com os demais órgãos da administração pública municipal, inclusive, no que diz respeito à captação de recursos financeiros.

É justamente esse contexto de atuação internacional de municípios enquanto instrumento de formulação e implementação de políticas públicas que se mostra necessária a investigação da existência ou não de controle por parte dos órgãos legitimados para tanto. No município de São Paulo, particularmente, tal fiscalização deveria ser feita pela Comissão de Relações Internacionais da Câmara Municipal de São Paulo.

Contudo, consultando-se as informações encaminhadas pela Câmara Municipal de São Paulo não foram encontrados elementos concretos indicando a existência de accountability da atuação internacional do município de São 
Paulo. Na legislatura 2013 a 2016 a Comissão não realizou qualquer audiência pública referente à atuação internacional da capital paulista, bem como não fez qualquer visita à Secretaria, além de não ter encaminhado à pasta qualquer ofício cobrando informações. De qualquer forma, o trabalho apontou para um dado interessante, qual seja, o pouco interesse dos vereadores de São Paulo quanto à atuação internacional, não obstante a inexistência de accountability da prática ser uma realidade preocupante, tendo em vista que o controle de todo 0 tipo de atuação pública ser fundamental em um regime democrático.

\section{REFERÊNCIAS}

BLANES SALA, José; SANTOS, Clara Maria Faria. O fundamento jurídico para a ação internacional do Município de São Paulo. In: BLANES SALA, José (Org.). O município e as relações internacionais: aspectos jurídicos. São Paulo: Educ, 2009.

BRASIL. Constituição da República Federativa, de 5 de outubro de 1988. Disponível em: <www.planalto.gov.br/ccivil_03/Constituicao/Constitui\%C3\%A7ao.htm>. Acesso em: 03 de ago. de 2016.

CAMPOS, Ana Maria. Accountability: quando poderemos traduzi-la para o português? Revista de Administração Pública, Rio de Janeiro, fev./abr. 1990.

CASTELO BRANCO, Álvaro Chagas Paradiplomacia e entes não centrais no cenário internacional. Curitiba: Juruá, 2008.

FONSECA, Marcela Garcia. Os entes federativos brasileiros frente ao direito internacional. 2013. Tese (Doutorado em Relações Internacionais) - Instituto de Relações Internacionais, Universidade de São Paulo, São Paulo, 2013.

JAKOBSEN, Kjeld. Poder local e relações internacionais. In: RODRIGUES, Gilberto Marcos Antônio; XAVIER, Marcos; ROMÃO, Wagner de Melo (Org.). Cidades em relações internacionais: análises e experiências brasileiras. São Paulo: Desatino, 2009.

KLEIMAN, Alberto; CEZARIO, Gustavo de Lima. Um olhar sobre a atuação internacional dos governos subnacionais. In: PINHEIRO, Letícia; MILANI, Carlos R.S (Org.). Política externa brasileira: a política das práticas e as práticas da política. Rio de Janeiro: Ed. FGV, 2011.

MOHN, Paulo Fernando. Autonomia municipal, centralização e liberdade. Revista de Informação Legislativa, Brasilia, no 171, p. 199-209, jul/set. 2006.

MOTA, Ana Carolina Yoshida Hirano de Andrade. Accountability no Brasil: os cidadãos e seus meios institucionais de controle dos representantes. Tese (Doutorado em Ciência Política). Universidade de São Paulo, São Paulo, 2006.

O'DONNELL, Guillermo. Accountability horizontal e novas poliarquias. Revista Lua Nova, ㄲo 44, 1998. 
PINHO, José Antônio Gomes de; SACRAMENTO, Ana Rita Silva. Accountability: já podemos traduzi-la para o português? Revista Administração Pública, v. 43, n. 6, Rio de Janeiro, nov./dez. 2009.

PRZEWORSKI, Adam. O Estado e o cidadão. In: PEREIRA, Luiz Carlos Bresser; WILHEIM, Jorge; SOLA, Lourdes (Orgs.). Sociedade e Estado em transformação. São Paulo: Editora UNESP, p. 123-145, 1999.

ROMÃO, Wagner de Melo. O novo contexto das relações internacionais e a ação externa das cidades brasileiras. In: RODRIGUES, Gilberto Marcos Antônio; XAVIER, Marcos; ROMÃO, Wagner de Melo (Org.). Cidades em relações internacionais: análises e experiências brasileiras. São Paulo: Desatino, 2009.

ROSA, Leonardo Barchini. A Secretaria Municipal de Relações Internacionais e Federativas de São Paulo. In: MARCOVITCH, Jacques; DALLARI, Pedro (Org.). Relações internacionais de âmbito subnacional: a experiência de estados e municípios no Brasil. São Paulo: Instituto de Relações Internacionais da Universidade de São Paulo, 2014.

SALOMÓN, Monica. A dimensão subnacional da política externa brasileira: determinantes, conteúdos e perspectivas. In: PINHEIRO, Letícia; MLANI, Carlos R.S (Org.). Política externa brasileira: a política das práticas e as práticas da política. Rio de Janeiro: FGV, 2011.

SÃO PAULO (MUNICÍPIO). Lei 9.167 de 03 de dezembro de 1980. Dispõe sobre a reorganização, competência, jurisdição e funcionamento do Tribunal de Contas do Município de São Paulo, e dá outras providências. Disponível em http://www.tcm.sp.gov.br/legislacao/lorgtcm/Lei_n9167.pdf Acesso em: 03 de ago. de 2016, 1980.

SÃO PAULO (MUNICÍPIO). Resolução oㅜ 2, de 26 de abril de 1991. Regimento Interno da Câmara Municipal de São Paulo. Disponível em <http://www.camara.sp.gov.br/wpcontent/uploads/2014/10/regimento-interno-2013-RC291C.pdf> Acesso em 17 de mar. de 2017, 1991.

SÃO PAULO (MUNICÍPIO). Lei 13.165 de 05 de julho de 2001. Cria a Secretaria Municipal de Relações Internacionais - SMRI e dá outras providências. Disponível em <http://camaramunicipalsp.qaplaweb.com.br/iah/fulltext/leis/L13165.pdf> Acesso em 03 de ago. de 2016, 2001.

SÃO PAULO (MUNICÍPIO). Lei no 15.764 de 27 de maio de 2013. Dispõe sobre a criação e alteração da estrutura organizacional das Secretarias Municipais que especifica.Disponível<http://www3.prefeitura.sp.gov.br/cadlem/secretarias/negocios_jr idicos/cadlem/integra.asp?alt=28052013L\%20157640000> Acesso em 03 de ago. de 2016, 2013.

SÃO PAULO (MUNICIPIO) Secretaria Municipal de Relações Internacionais e Federativas de São Paulo. Assuntos internacionais: acordos de cooperação bilateral. São Paulo, [2015], Disponível em: <http://www.prefeitura.sp.gov.br/cidade/secretarias/relacoes_internacionais/assuntos_i nternacionais/index.php?p=146131>. Acesso em: 11 set. 2016. 
SCHEDLER, Andreas. Conceptualizing Accountability. In: SCHEDLER, Andreas; DIAMOND, Larry and PLATTNER, Marc F (Eds.) The Self-Restraining State: Power and Accountability in New Democracies. London: Lynne Rienner Publishers, 1999.

VIGEVANI, Tullo. Problemas para a atividade internacional das unidades subnacionais: estados e municípios brasileiros. Revista Brasileira de Ciências Sociais, São Paulo, v. 21, n. 62, p. 127-169, 2006.

; PRADO, Débora Figueiredo B. Ações e problemas da paradiplomacia no Brasil. In: BLANES SALA, José; GASPAROTO, Ana Lúcia (Org.) Relações internacionais: polaridade e novos/velhos temas emergentes. Marilia: Educ: Ed. UNESP: Oficina Universitária, 2010.

Recebido em 24 de julho de 2017. Aprovado em 09 de dezembro de 2017. 